\title{
Efecto del desgomado y la temperatura sobre la eclosión de huevos del bagre, Pangasianodon hypophthalmus
}

\author{
José Antonio Estrada-Godinez ${ }^{*} \bowtie\left(\mathbb{0} ;\right.$; Gustavo Alejandro Rodríquez-Montes-de-Oca1 ${ }^{凶(\mathbb{0} ;}$;

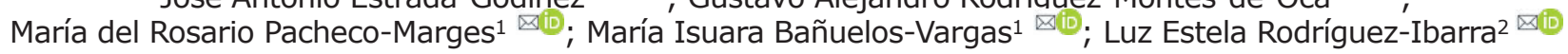

${ }^{1}$ Universidad Autónoma de Sinaloa, Facultad de Ciencias del Mar. Paseo Claussen s/n, Col. Los Pinos, Mazatlán, Sinaloa, México. ${ }^{2}$ Centro de Investigación en Alimentación y Desarrollo, Unidad Mazatlán en Acuicultura y Manejo Ambiental. Sinaloa, México. Correspondencia: joseestrada@uas.edu.mx

Recibido: Noviembre 2020; Aceptado: Mayo 2021; Publicado: Junio 2021.

\section{RESUMEN}

Objetivo. El propósito del presente trabajo fue evaluar el efecto del ácido tánico y de las proteasas para eliminación de la capa adherente en huevos fecundados de bagre asiático, $P$. hypophthalmus, para mejorar las condiciones de incubación. Materiales y métodos. Se utilizó ácido tánico a 0.5 $\mathrm{g} \mathrm{L}^{-1}$ por $5 \mathrm{~min}$, proteasa a $5 \mathrm{~mL} \mathrm{~L}^{-1}$ por $8 \mathrm{~min}$ para la eliminación de la capa adherente de huevos fecundados y un grupo control, sin la adición de estos químicos. Todos los tratamientos fueron incubados a 26,28 y $30^{\circ} \mathrm{C}$, para determinar el porcentaje de eclosión. Todos los tratamientos fueron realizados por triplicado. Resultados. Los huevos tratados con proteasa no eclosionaron en ninguna temperatura de incubación, mientras que los tratados con ácido tánico e incubados a 26 y $28^{\circ} \mathrm{C}$ tuvieron porcentajes de eclosión mayor al $60 \%$, siendo los porcentajes de eclosión más altos $(84.7 \pm 1.3 \%)$ los que se obtuvieron a $28^{\circ} \mathrm{C}$. Los huevos del grupo control presentaron los porcentajes de eclosión significativamente más altos $(14.2 \pm 0.6 \%)$ cuando fueron incubados a $28^{\circ} \mathrm{C}$ que a $26030^{\circ} \mathrm{C}$. Conclusiones. Los resultados mostraron una significativa interacción entre el tipo de desgomado y de la temperatura de incubación, indicando que el ácido tánico produce el mejor porcentaje de eclosión a los $28^{\circ} \mathrm{C}$.

Palabras clave: Ácido tánico; capa adherente; porcentaje de eclosión proteasa; temperatura de incubación (Fuente: ICYT de Biología Animal).

\section{ABSTRACT}

Objective. This study aimed to assess the effect of tannic acid and protease on the elimination of adhesiveness in fertilized eggs of striped catfish, $P$. hypophthalmus, to improve the incubation conditions. Materials and methods. Tannic acid at $0.5 \mathrm{~g} \mathrm{~L}^{-1}$ for 5 min and protease at $5 \mathrm{~mL} \mathrm{~L}^{-1}$ for 8 min were used to eliminate the adhesive coat of fertilized eggs, and a control group was used without chemical addition. Then, the eggs from all treatments were incubated at 26,28 , and $30^{\circ} \mathrm{C}$. Results. The eggs treated with protease did not hatch at any temperature, while in eggs treated with tannic acid and incubated at 26 and $28^{\circ} \mathrm{C}$, hatching rates above $60 \%$ were observed, where those eggs incubated at $28^{\circ} \mathrm{C}(84.7 \pm 1.3 \%)$ had the highest hatching rates $(p<0.05)$ among all the

Como citar (Vancouver).

Estrada-Godinez JA, Rodríguez-Montes-de-Oca GA, Pacheco-Marges MR, Bañuelos-Vargas MI, Rodríguez-Ibarra LE. Efecto del desgomado y la temperatura sobre la eclosión de huevos del bagre, Pangasianodon hypophthalmus. Rev MVZ Córdoba. 2021; 26(3):e2220. https://doi.org/10.21897/rmvz.2220

CEl (los) autor (es), Revista MVZ Córdoba 2021. Este artículo se distribuye bajo los términos de la licencia internacional Creative Commons Attribution CC) $\$ 4.0$ (https://creativecommons.org/licenses/by-nc-sa/4.0/), que permite a otros distribuir, remezclar, retocar, y crear a partir de su obra de modo no BY NC SA comercial, siempre y cuando den crédito y licencien sus nuevas creaciones bajo las mismas condiciones. 
treatments. The eggs of the control group had significantly higher hatching percentages (14.2 \pm $0.6 \%$ ) when they were incubated at $28^{\circ} \mathrm{C}$ than at 26 or $30^{\circ} \mathrm{C}$. Conclusions. The results showed a significant interaction between the type of degumming and the incubation temperature, indicating that tannic acid produces the best hatching percentage at $28^{\circ} \mathrm{C}$.

Keywords: Adhesive coat; hatching rate; incubation temperature; protease; tannic acid (Source: ICYT de Biología Animal).

\section{INTRODUCCIÓN}

Los huevos de los peces teleósteos están rodeados por una envoltura compuesta de dos capas: una zona radiata interna de naturaleza protéica y que tiene funciones protectoras, y una zona radiata externa compuesta por mucoplisacáridos que, en algunos peces como los siluriformes, se presenta una capa gelatinosa que sirve para adherir los huevos a los sustratos donde son puestos $(1,2)$. En particular, los huevos de bagre asiático, $P$. hypophthalmus, son pelágicos, ligeramente ovalados y se adhieren unos a otros o algún sustrato, lo cual les permite no ser arrastrados por las corrientes (3). No obstante, para la producción acuícola, la formación de la capa adherente trae consecuencias negativas como baja oxigenación y el desarrollo de agentes patógenos, lo que puede reflejarse en bajas tasas de eclosión y supervivencia larval (4). Sin embargo, y pese a la importancia comercial del cultivo de bagre asiático, poco se ha explorado el mejoramiento de su porcentaje de eclosión.

Para la eliminación de la capa adherente de los huevos en aquellas especies de peces que presentan dicha característica, se han empleado diversos métodos, desde tratamientos mecánicos como la agitación de los huevos para separarlos como en la lucioperca americana, Stizostedion vitreum (5), el empleo de productos naturales como arena, arcilla, leche en polvo y jugo de piña, para el desgomado de huevos de tenca, Tinca tinca (6); lucioperca, Sander lucioperca (7) y botete diana, Sphoeroides annulatus $(8,9)$, hasta la aplicación de tratamientos químicos como urea, sulfito de sodio, enzimas proteolíticas y ácido tánico, en el desgomado de huevos de lucioperca, S. lucioperca (10) vaqueta, Labrus bergylta (11), bagre africano, Clarias gariepinus (12), trucha arcoiris, Oncorhynchus mykiss (13), tenca, T. tinca (14), lucioperca, S. lucioperca (15) y esperlano arcoiris, Osmerus mordax (16).

Por otro lado, el manejo de la temperatura es fundamental para la incubación exitosa de huevos, debido a que es de los factores que más afectan varios aspectos del desarrollo embrionario y larval, el crecimiento, las tasas de fecundación y eclosión y la eficiencia en el uso de energía metabólica $(17,18)$.

Debido a ello, el objetivo de este trabajo fue evaluar el efecto del ácido tánico y la proteasa, sobre la eliminación de la adhesividad de huevos de bagre asiático, $P$. hypophthalmus, así como el efecto de distintas temperaturas de incubación, sobre el porcentaje de eclosión.

\section{MATERIALES Y MÉTODOS}

Manejo de organismos. El presente trabajo se realizó en el laboratorio de "Biotecnología Acuícola Sustentable" de la Facultad de Ciencias del Mar, perteneciente a la Universidad Autónoma de Sinaloa. A partir de reproductores mantenidos bajo condiciones naturales de luz y temperatura $\left(23^{\circ} 12^{\prime} 31.7^{\prime \prime} \mathrm{N} \mathrm{y}-106^{\circ} 25^{\prime} 28.18^{\prime \prime} \mathrm{W}\right)$ y alimentados al $3 \%$ de la biomasa con una dieta comercial (35\% de proteína, Purina Nutripec ${ }^{\circledR}$ ), se eligieron dos hembras (61 y $61.5 \mathrm{~cm}$ de longitud total; 2248 y $2538 \mathrm{~g}$ de peso) con un diámetro modal de ovocitos $\geq 1 \mathrm{~mm}$ y un macho $(60.5 \mathrm{~cm}$ de longitud total y $2190 \mathrm{~g}$ de peso) con presencia de esperma fluyente. Se indujo el desove mediante la aplicación de Gonadotropina Coriónica Humana (HCG, Chorulon ${ }^{\circledR}$ ). A las hembras se les aplicaron dos dosis, la primera de 500 U.I. $\mathrm{Kg}^{-1}$ de peso corporal y una segunda de 2000 U.I. $\mathrm{Kg}^{-1}, 8$ horas después. Al macho se le aplicó una dosis de HCG de 2000 U.I. $\mathrm{Kg}^{-1}$ al momento de aplicarle a las hembras la segunda inyección. Doce horas después, se realizó la obtención de gametos y la fertilización de ovocitos, utilizando el método seco (19).

Diseño experimental. Los desoves obtenidos de ambas hembras se mezclaron y posteriormente se dividió en tres partes. Cada porción de desove se sometió a los siguientes tratamientos para la eliminación de la capa adherente: 1) Huevos sin desgomar (control), 2) Huevos tratados con $0.5 \mathrm{~g} \mathrm{~L}^{-1}$ de ácido tánico por 5 min y 3) Huevos tratados con 5 $\mathrm{mL} \mathrm{L}^{-1}$ de enzima proteolítica de Aspergillus oryzae, $\geq 500 \mathrm{Ug}^{-1}$ (Sigma Aldrich ${ }^{\circledR}$ P6110), por 8 min. 
Después de aplicar los tratamientos, los huevos fueron lavados tres veces con agua corriente. De cada tratamiento de desgomado, se tomaron muestras de 850 huevos cada una, las cuales fueron puestas en frascos de cristal de $1 \mathrm{~L}$ con aireación constante y se incubaron a 26, 28 y $30^{\circ} \mathrm{C}$. La incubación se realizó por triplicado para cada antiadherente y cada temperatura. Después de 24 horas se estimó el porcentaje de eclosión de la siguiente manera:

$\%$ de eclosión = (número de larvas/número inicial de huevos) $\times 100$.

Análisis estadístico. Con la finalidad de evaluar el efecto de los tratamientos de desgomado de huevos fecundados, de las temperaturas de incubación y de su interacción sobre el porcentaje de eclosión, se realizó un análisis de varianza de dos vías con prueba de Holm-Sidak para verificar las diferencias significativas entre los tratamientos. Previo al análisis estadístico, los datos de porcentaje se transformaron mediante la raíz cuadrada del arco seno. La prueba estadística se llevó a cabo con un nivel de significancia de $a=0.05$.

Aspectos éticos. Los procedimientos realizados a los organismos en este estudio, se llevaron a cabo de acuerdo con la legislación mexicana vigente en la Ley General de Bienestar Animal, Título 5, Capítulo III, publicada el 11 de febrero de 2016.

\section{RESULTADOS}

Los resultados obtenidos se representan en la figura 1 , en donde se observan que cada factor (desgomado y temperatura) como su interacción, produjo efectos altamente significativos $(p<0.001)$ sobre el porcentaje de eclosión de los huevos del bagre asiático.

Por otra parte, los huevos tratados con proteasa, para la eliminación de la adhesividad, no eclosionaron en ninguna de las temperaturas de incubación. No obstante, los huevos tratados con ácido tánico e incubados a 26 y $28^{\circ} \mathrm{C}$ presentaron porcentajes de eclosión por arriba del $60 \%$, siendo los huevos incubados a $28^{\circ} \mathrm{C}$, los que presentaron los porcentajes de eclosión significativamente más altos ( $84.7 \pm 1.3 \%)$; mientras que los huevos incubados a $30^{\circ} \mathrm{C}$ presentaron porcentajes de


dentro de este antiadherente. En el tratamiento control, se obtuvieron porcentajes de eclosión por debajo del $20 \%$ para las 3 temperaturas de incubación, siendo una vez más, los huevos incubados a $28^{\circ} \mathrm{C}$ los que presentaron las

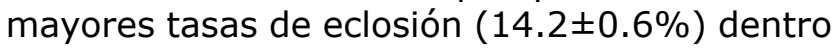
de este grupo (Figura 1).

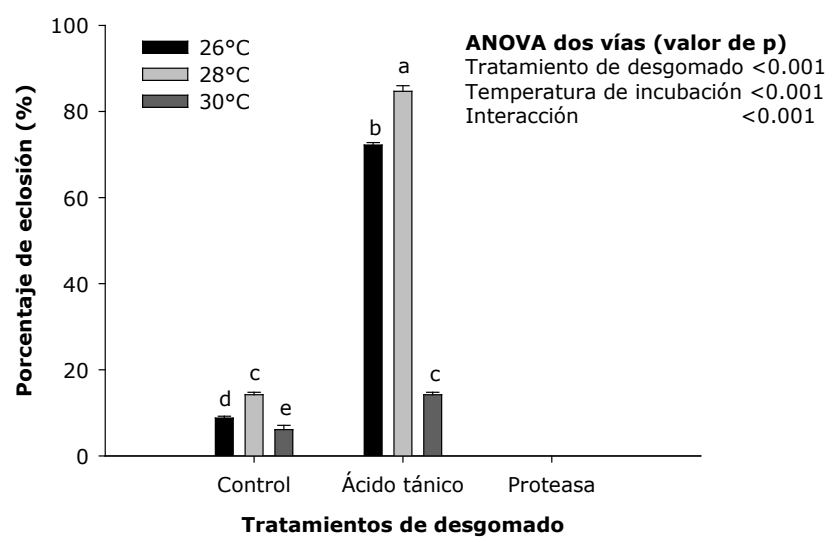

Figura 1. Porcentaje de eclosión de huevos de $P$. hypophthalmus, (media \pm desviación estándar) tratados con ácido tánico ( $\mathrm{n}=$ 850 huevos), proteasa ( $n=850$ huevos) y sin tratamiento o control ( $n=850$ huevos) e incubados a diferentes temperaturas. Letras distintas sobre las barras significan diferencias significativas $(p<0.05)$.

\section{DISCUSIÓN}

De acuerdo con el presente trabajo, se puede observar que la eliminación de la capa adherente de huevos del bagre asiático, $P$. hypophthalmus con ácido tánico e incubados a $28^{\circ} \mathrm{C}$, mejoran sustancialmente la eclosión $(84.7 \pm 1.3 \%)$. Porcentajes de eclosión similares, entre 80-85 $\%$, fueron reportados en beluga, Huso huso, cuando emplearon también ácido tánico a una concentración de $0.5 \mathrm{~g} \mathrm{~L}^{-1} \mathrm{y}$ un tiempo de exposición de 1.5 minutos en huevos de esta especie (20). También se reportaron porcentajes de eclosión superiores al $80 \%$ en la lucioperca, Sander lucioperca, al eliminar la capa adherente de los huevos con ácido tánico a una concentración de $0.75 \mathrm{~g} \mathrm{~L}^{-1} \mathrm{y}$ un tiempo de exposición entre uno y dos minutos (10). No obstante, porcentajes de eclosión menores al 5\% fueron reportados en bagre africano, Clarias gariepinus, cuando emplearon ácido tánico a la misma concentración utilizada en este trabajo, pero con un tiempo de exposición de $0.5 \mathrm{~min}$ (12). Lo que sugiere que para un efecto eficiente del ácido tánico en el desgomado de los huevos de bagre puede ser necesario un mayor tiempo de exposición, como el que se hizo en este trabajo. 
Los huevos tratados con proteasa a $5 \mathrm{~mL} \mathrm{~L}^{-1}$ por 8 min no llegaron a eclosionar a ninguna de las temperaturas expuestas. Lo cual difiere de lo encontrado en botete diana, Sphoeroides annulatus, donde se obtuvieron porcentajes de eclosión de $93.03 \pm 3.01 \%$ cuando emplearon esta enzima a la misma concentración y tiempo de exposición (9). Por su parte, en huevos de lucioperca, $S$. lucioperca, se observaron porcentajes de eclosión de $85.4 \%$ al utilizar proteasa alcalina a $1.5 \mathrm{~mL} \mathrm{~L}^{-1}$ por 2 min (15). Así mismo, en tenca, Tinca tinca, se obtuvieron porcentajes de eclosión mayores al 95\% al eliminar la capa adherente con proteasa alcalina a $8 \mathrm{~mL} \mathrm{~L}^{-1}$ con un tiempo de exposición de un minuto (14). De acuerdo con lo anterior y con los resultados obtenidos, se recomienda probar menores concentraciones de enzima proteolítica y/o tiempos de exposición para lograr altos porcentajes de eclosión durante el desgomado de los huevos de $P$. hypophthalmus, esto debido a que tal vez la concentración utilizada en este trabajo fue muy alta o el tiempo de exposición fue demasiado largo, causando daños en la estructura de los huevos, alterando así el desarrollo embrionario.

Con respecto a la temperatura de incubación, se ha demostrado para muchas especies que, al incrementar la temperatura dentro de un rango óptimo, se acelera el desarrollo embrionario y, por lo tanto, el tiempo de eclosión se acorta. El rango óptimo depende de las características biológicas y ecológicas de cada especie, donde las temperaturas de incubación fuera de tales rangos tienen efectos negativos sobre la eclosión de los huevos y la supervivencia de las larvas (21). En un estudio donde se incubaron huevos de carpa común, Cyprinus carpio, a las mismas temperaturas empleadas en este trabajo, los porcentajes de eclosión más altos se obtuvieron a $26^{\circ} \mathrm{C}(98.79 \pm 1.23 \%)(22)$, lo cual es superior a lo obtenido en el presente estudio a dicha temperatura (72.2 $\pm 0.6 \%)$. No obstante, en el Pangasius sutchi, se reportaron porcentajes de eclosión entre $76 \pm 3.0 \%$ a una temperatura promedio de $28.5^{\circ} \mathrm{C}(23)$, mientras que en este estudio se obtuvieron porcentajes de eclosión de $84.7 \pm 1.3 \%$ a $28^{\circ} \mathrm{C}$, lo cual es ligeramente superior a lo registrado por Chad et al (23).

En conclusión, para el bagre asiático, $P$. hypophthalmus, el tratamiento de huevos fecundados con ácido tánico a una concentración de $0.5 \mathrm{~g} \mathrm{~L}^{-1}$ con un tiempo de exposición de cinco minutos e incubados a $28^{\circ} \mathrm{C}$, incrementa significativamente el porcentaje de eclosión.

\section{Conflicto de intereses}

Los autores declaran no tener conflicto de intereses.

\section{Agradecimientos}

Los autores agradecemos al proyecto PROFAPIUAS 2015/096 por el financiamiento para la realización del trabajo aquí presentado.

\section{REFERENCIAS}

1. Riehl R, Patzner RA. Minireview: The modes of egg attachement in teleost fishes. Ital J Zool. 1998; 65(S1):415-420. https://doi. org/10.1080/11250009809386857

2. da Rocha-Perini V, Sato Y, Rizzo E, Bazzoli N. Biology of eggs, embryos and larvae of Rhinelepis aspera (Spix \& Agassiz, 1829) (Pisces: Siluriformes). Zygote. 2009; 18:159-171. https://doi.org/10.107/ $\underline{\text { S0967199409990165 }}$
3. Ali $\mathrm{H}$, Haque MM, Belton B. Striped catfish (Pangasianodon hypophthalmus, Sauvage, 1878) aquaculture in Bangladesh: an overview. Aquac. Res. 2012; 44(6):950956. https://doi.org/10.1111/j.13652109.2012.03101.x

4. Siddique MAM, Cosson J, Psenicka M, Linhart $O$. A review of the structure of sturgeon egg membranes and of the associated terminology. J Appl Ichthyol. 2013; 30(6):1246-1255. https://doi. org/10.1111/jai.12604 
5. Krise WF, Bulkowski-Cummings $L$, Shellman AD, Kraus KA, Gould RW. Increased Walleye Egg Hatch and Larval Survival after Protease Treatment of Eggs. Prog Fish Cult. 1986; 48(2):95100. http://dx.doi.org/10.1577/1548640(1986)48<95:IWEHAL $>2.0$. CO ;2

6. Gela D, Linhart O, Flajshans M, Rodina M. Egg incubation time and hatching success in tench Tinca tinca (L.) related to the procedure of egg stickness alimination. J Appl Ichthyol. 2003; 19(3):132-133. https://doi. org/10.1046/j.1439-0426.2003.00465.x

7. Ljubobratovic U, Csengeri I, Kucska B, Balogh E, Lengyel S, Kovács G, Adorjan A, Feledi T, Janurik E, Rónyai A. Comparison of the Procedures for Adhesiveness Removal in Pikeperch (Sander lucioperca) Eggs with Special Emphasis on the Effect of Tannic Acid. Turkish J Fish Aquat Sci. 2017; 17:461-469. https://doi.org/10.4194/1303$\underline{2712-v 17 \quad 3 \quad 02}$

8. Rodríguez-Ibarra LE, Abdo-de la Parra MI, Rodríguez-Montes de Oca GA, MorenoHernández MS, Velasco-Blanco G, GarcíaAguilar N, Álvarez-Lajonchere LS. Evaluación de métodos para la eliminación de la capa adherente de los huevos de botete diana Sphoeroides annulatus (Pisces: Tetraodontidae). Rev Biol Mar Oceanogr. 2010; 45(1):147-151. http://dx.doi. org/10.4067/S0718-19572010000100015

9. Rodríguez-Ibarra LE, Abdo-de la Parra MI, Velasco-Blanco G, González-Rodríguez BT, Domínguez-Jiménez P, García-Aguilar N, Ibarra-Castro L. Efecto de la eliminación de la capa adherente de los huevos utilizando enzima proteolítica proteasa y jugo de piña en la larvicultura del botete diana Sphoeroides annulatus. Rev Biol Mar Oceanogr. 2013; 48(2):379-385. http://dx.doi.org/10.4067/ $\underline{\text { S0718-19572013000200017 }}$

10. Zarski D, Krejszeff S, Kucharczyk D, PalinskaZarska K, Targonska K, Kupren K, Fontaine $\mathrm{P}$, Kestemont P. The application of tannic acid to the elimination of egg stickiness at varied moments of the egg swelling process in pikeperch, Sander lucioperca (L.). Aquac Res. 2015; 46(2):324-334. https://doi. org/10.1111/are.12183
11. Grant B, Picchi N, Davie A, Leclercq $E$, Migaud $H$. Removal of the adhesive gum layer surrounding naturally fertilised ballan wrasse (Labrus bergylta) eggs. Aquaculture. 2016; 456:44-49. https://doi. org/10.1016/j.aquaculture.2016.01.016

12. Kareem OK, Ajani EK, Akintunde MA, Olanrewaju AN, Oduntan OB. Effect of Different Fertilization and Egg De-adhesion Methods on Hatching and Survival of Clarias gariepinus (Burchell 1822) Fry. J Fishscicom. 2017; 11(1):21-27. http:// dx.doi.org/10.21767/1307-234X.1000103

13. Wagner EJ, Oplinger RW, Bartley $M$. Evaluation of Tannic Acid for Disinfection of Rainbow Trout Eggs. N Am J Aquacult. 2012; 74(1):80-83. http://dx.doi.org/10.1080/15 $\underline{222055.2011 .649393}$

14. Carral JM, Celda JD, Sáez-Royuela M, Rodríguez R, Aguilera A, Melendre, $P$. Effects of four egg desticking procedures on hatching rate and further survival and growth of larvae in the tench (Tinca tinca L.). Aquac Res. 2006; 37(6):632-636. https://doi. org/10.1111/j.1365-2109.2006.01473.x

15. Kristan J, Blecha M, Policar T. Alcalase treatment for elimination of stickness in pikeperch (Sander lucioperca) eggs under controlled conditions. Aquac Res. 2015; 47(12):3998-4003. https://doi. org/10.1111/are.12850

16. Walker, A.B., Ward, D., Duclos, K., Peters, M., Belinsky, D.L. Surface Disinfection and Removal of Adhesiveness from Rainbow Smelt Eggs. N Am J Aquacult. 2010; 72(2):158-163. http://dx.doi.org/10.1577/ A09-047.1

17. Brown CA, Gothreaux CT, Green CC. Effects of temperature and salinity during incubation on hatching and yolk utilization of Gulf killfish Fundulus grandis embryos. Aquaculture. 2011; 315(3-4):335-339. https://doi. org/10.1016/j.aquaculture.2011.02.041 
18. Estrada-Godinez JA, Moreno-Figueroa LD, Maldonado-García M, Urbiola-Pérez JC, Rodríguez-Romero J, Audelo-Naranjo $\mathrm{JM}$. Influence of the temperature on the early larval development of the Pacific red snapper, Lutjanus peru (Nichols \& Murphy, 1922). Lat Am J Aquat Res. 2015; 43(1):137-145. http://dx.doi.org/10.3856/ vol43-issue1-fulltext-12.

19. Legendre M, Linhart O, Billard R. Spawning and management of gametes, fertilized eggs and embryos in Siluroidei. Aquat Living Resour. 1996; 9:59-80. https://doi. org/10.1051/alr: 1996042

20. Hosseini SH, Khara H. Effect of two egg de-adhesion methods on reproductive successes of beluga Huso huso. Rivarstvo. 2015; 73(1):26-29. http://dx.doi. org/10.14798/73.1.794
21. Bobe J, Labbé C. Egg and sperm quality in fish. Gen Comp Endocr. 2010; 165(3):535-548. https://doi.org/10.1016/j. ygcen.2009.02.011

22. Sapkale $P H$, Singh RA, Desai AS. Optimal water temperature and $\mathrm{pH}$ for development of eggs and growth of spawn of common carp (Cyprinus carpio). J Appl Anim Res. 2011; 39(4):339-345. https://doi.org/10. $\underline{1080 / 09712119.2011 .620269}$

23. Chad BK, Singh MK, Mandal B. Studies on the breeding of Pangasius sutchi using different inducing agents. J Appl Aquac. 2011; 23(1):32-40. https://doi.org/10.10 $\underline{80 / 10454438.2011 .549782}$ 